\title{
Pain perception and brain evoked potentials in patients with angina despite normal coronary angiograms
}

\author{
Ole Frøbert, Lars Arendt-Nielsen, Peter Bak, Peter Funch-Jensen, Jens Peder Bagger
}

\begin{abstract}
Objective-To evaluate the role of nociception in patients with angina despite normal coronary angiograms and to investigate whether any abnormality is confined to visceral or somatosensory perception.

Methods-Perception, pain threshold, and brain evoked potentials to nociceptive electrical stimuli of the oesophageal mucosa and the sternal skin were investigated in 10 patients who had angina but normal coronary angiograms, no other signs of cardiac disease, and normal upper endoscopy. Controls were 10 healthy volunteers. The peaks of the evoked potential signal were designated $\mathbf{N}$ for negative deflections and $P$ for positive. Numbers were given to the peaks in order of appearance after the stimulus. The peak to peak amplitudes (P1/N1, N1/P2) were measured in $\mu \mathrm{V}$.
\end{abstract}

Results-(1) Angina pectoris was provoked in seven patients following continuous oesophageal stimulation. (2) Distant projection of pain occurred after continuous electrical stimulation of the oesophagus in four patients and in no controls. (3) Patients had higher oesophageal pain thresholds (median 16.3 mA $v 7.3 \mathrm{~mA}, P$ $=0.02$ ) to repeated stimuli than controls, whereas the values did not differ with respect to the skin. There were no intergroup differences in thresholds to single stimuli. (4) Patients had substantially reduced brain evoked potential amplitudes after both single oesophageal (P1/N1, median values: $7 \cdot 2 \mu \mathrm{V}$, controls: 29.0 $\mu \mathrm{V}$; N1/P2: $16.5 \mu \mathrm{V}$, controls: $66.0 \mu \mathrm{V}$; $P<0.001$ for both) and skin (N1/P2: 13.5 $\mu \mathrm{V}$; controls: $76.0 \mu \mathrm{V} ; \mathrm{P}<0.001)$ stimuli despite the similar pain thresholds.

Conclusion-Central nervous system responses to visceral and somatosensory nociceptive input are altered in patients who have angina despite normal coronary angiograms.

(Heart 1996;75:436-441)

Keywords: angina pectoris; electrical stimulation; nociception; stimulus-response

Several pathophysiological explanations have been suggested for the pain syndrome in patients with angina and normal coronary angiograms: abnormal cardiac nociception following intracardiac catheter manipulation ${ }^{12}$ or intracoronary adenosine infusion ${ }^{3}$; reduced capacity of minor coronary vessels to dilate ${ }^{4}$; a generally elevated sympathetic activation ${ }^{56}$; gastrooesophageal reflux $^{7}$ and oesophageal motility disturbances ${ }^{8}$; a combination of oesophageal and cardiac aetiology ${ }^{9}$; insulin resistance ${ }^{10}$; psychiatric illness ${ }^{11-13}$; and musculo-skeletal disorders of the chest. ${ }^{14-16} \mathrm{~A}$ general abnormality of nociception could incorporate many of the results from previous studies $^{17}$ and recently this hypothesis has found support in a clinical trial where imipramine, a cyclic antidepressant with general antinociceptive properties, given to patients with angina and normal coronary angiograms resulted in a reduction of pain episodes. ${ }^{18}$

In order to evaluate the role of nociception further and to investigate whether any abnormalities are confined to visceral or somatosensory perception, we employed an experimental model of electrical stimulation of the oesophageal mucosa and the presternal skin in patients with angina despite normal coronary angiograms and in healthy controls. The applied stimuli were evaluated by brain evoked potentials, which facilitates a quantitative measure of the central responses. ${ }^{19} 20$

\section{Methods}

SUBJECTS

Five women and five men (median age 55 years, range 40 to 67 ) with angina of median two years duration were studied. All had a normal resting electrocardiogram. No patients had evidence of left ventricular hypertrophy or valvar heart disease on echocardiography, all had normal coronary angiogram with left ventricular ejection fraction $>50 \%$, and none had electrocardiographic signs of coronary vasospasm, either spontaneously or in response to hyperventilation. ${ }^{21}$ Evaluation of cardiac metabolism during atrial pacing ${ }^{22}$ did not show lactate production in any patient. Five of the 10 patients had an abnormal response to exercise testing ( $\geqslant 1 \mathrm{~mm}$ horizontal or downsloping ST segment depression on the electrocardiogram). Further cardiological characteristics are listed in table 1. Oesophago-gastro-duodenoscopy revealed no erosive or exudative oesophagitis, gastritis, duodenitis, peptic ulcers, or malignancy. The cardiological and gastrointestinal investigations were carried out three to 12 months 
Table 1 Characteristics of 10 patients with angina despite normal coronary angiograms

\begin{tabular}{|c|c|c|c|c|c|c|c|c|c|c|c|c|c|c|c|}
\hline Patient & $\begin{array}{l}\text { Age } \\
\text { (years) }\end{array}$ & Sex & $\begin{array}{l}\text { Duration } \\
\text { (months) }\end{array}$ & $\begin{array}{l}\text { Pain } \\
\text { frequency } \\
\text { (attacks/ } \\
\text { month) }\end{array}$ & $\begin{array}{l}\text { Referred } \\
\text { pain }\end{array}$ & $\begin{array}{l}\text { Exercise } \\
\text { ECG }\end{array}$ & $\begin{array}{l}\text { Ejection } \\
\text { fraction } \\
(\%)\end{array}$ & $\begin{array}{l}\text { Systolic } \\
\text { BP } \\
(\mathrm{mm} \mathrm{Hg})\end{array}$ & $\begin{array}{l}\text { Diastolic } \\
\mathrm{BP} \\
(\mathrm{mm} \mathrm{Hg})\end{array}$ & $\begin{array}{l}\text { Cholesterol } \\
\text { (mmol/l) }\end{array}$ & $\begin{array}{l}H D L \\
\text { (mmolll) }\end{array}$ & $\begin{array}{l}\text { Triglycerides } \\
\text { (mmolll) }\end{array}$ & $\beta$ blockers & $\begin{array}{l}\text { Calcium } \\
\text { antagonists }\end{array}$ & sitrates \\
\hline $\begin{array}{r}1 \\
2 \\
3 \\
4 \\
5 \\
6 \\
7 \\
8 \\
9 \\
10\end{array}$ & $\begin{array}{l}49 \\
53 \\
56 \\
67 \\
58 \\
56 \\
52 \\
40 \\
53 \\
57\end{array}$ & $\begin{array}{l}M \\
F \\
M \\
F \\
M \\
M \\
M \\
F \\
F \\
F\end{array}$ & $\begin{array}{l}7 \\
61 \\
24 \\
15 \\
20 \\
36 \\
71 \\
16 \\
25 \\
24\end{array}$ & $\begin{array}{r}8 \\
90 \\
120 \\
60 \\
60 \\
90 \\
180 \\
120 \\
12 \\
60\end{array}$ & $\begin{array}{l}+ \\
+ \\
+ \\
+ \\
+ \\
+ \\
+ \\
+ \\
+ \\
+\end{array}$ & $\begin{array}{l}\text { Positive } \\
\text { Normal } \\
\text { Positive } \\
\text { Normal } \\
\text { Normal } \\
\text { Normal } \\
\text { Positive } \\
\text { Positive } \\
\text { Normal } \\
\text { Positive }\end{array}$ & $\begin{array}{l}68 \\
65 \\
65 \\
83 \\
75 \\
80 \\
62 \\
77 \\
65 \\
82\end{array}$ & $\begin{array}{l}110 \\
100 \\
140 \\
160 \\
130 \\
125 \\
160 \\
105 \\
110 \\
120\end{array}$ & $\begin{array}{l}80 \\
70 \\
80 \\
90 \\
70 \\
80 \\
90 \\
70 \\
70 \\
80\end{array}$ & $\begin{array}{l}5 \cdot 4 \\
8 \cdot 1 \\
4 \cdot 6 \\
6 \cdot 2 \\
6 \cdot 2 \\
6 \cdot 2 \\
6 \cdot 3 \\
6 \cdot 0 \\
6 \cdot 9 \\
\text { ND }\end{array}$ & $\begin{array}{l}1.01 \\
1.76 \\
1.06 \\
0.90 \\
0.80 \\
1.03 \\
1.21 \\
1.65 \\
1.54 \\
\text { ND }\end{array}$ & $\begin{array}{l}\text { ND } \\
1.06 \\
1.07 \\
1.69 \\
2.30 \\
2 \cdot 10 \\
1.53 \\
1 \cdot 14 \\
1.87 \\
\text { ND }\end{array}$ & $\begin{array}{l}+ \\
+ \\
- \\
+ \\
- \\
+ \\
+ \\
+ \\
+\end{array}$ & $\begin{array}{l}+ \\
- \\
+ \\
+ \\
+ \\
+ \\
- \\
- \\
+ \\
+\end{array}$ & $\begin{array}{l}+ \\
- \\
+ \\
- \\
+ \\
- \\
- \\
+ \\
+\end{array}$ \\
\hline
\end{tabular}

Duration, disease duration; HDL, high density lipoprotein cholesterol; ND, not done.

before the present study. All medication was withdrawn $72 \mathrm{~h}$ before the study. Five women and five men (median age 49 years, range 33 to 59) served as controls. They were free of cardiopulmonary symptoms, were normal on clinical investigation, had a normal response to exercise electrocardiographic testing and no history of gastrointestinal or cardiologic diseases, and were on no treatment. None of the patients or controls had neurological or endocrinological disorders.

\section{ELECTRICAL STIMULATION}

Electrical stimulation of the oesophageal mucosa $38 \mathrm{~cm}$ from the nostrils was delivered through a bipolar electrode as described previously. ${ }^{19}$ Stimuli were short trains of square wave pulses (each stimulus consisted of five pulses of $1 \mathrm{~ms}$ duration separated by $4 \mathrm{~ms}$ ) delivered by a computer controlled constant current stimulator. Before measurements, test stimuli were applied to make subjects familiar with the study regimen. Three thresholds were determined: (1) the threshold of perception; (2) the pain threshold; (3) the pain threshold of summation by applying five stimuli trains separated by $0.5 \mathrm{~s}$ (each stimulus consisted of five pulses of $1 \mathrm{~ms}$ duration separated by 4 $\mathrm{ms})$ : the threshold where the persons described the repeated nociceptive stimuli as increasingly painful through the series. At the end of the stimulation series a continuous 40 $\mathrm{Hz}$ stimulation (each pulse of $1 \mathrm{~ms}$ duration) was applied and the stimulus intensity was slowly increased until the subject asked for termination due to discomfort. The persons were asked to describe the sensations after single and continuous stimulation but they were not provided with descriptive words. Thereafter the patients were asked to answer "yes" or "no" depending on whether the sensations were similar to their usual episodes of angina.

Cutaneous stimuli were delivered through a surface electrode (Dantec 13L22, Copenhagen, Denmark) with $23 \mathrm{~mm}$ between the two saline soaked felt tips ( $3 \mathrm{~mm}$ diameter) placed at the sternum $12 \mathrm{~cm}$ distal to the jugular incisure. Cutaneous stimuli characteristics were identical to the oesophageal stimuli (short trains of square wave pulses, five per stimulus each of $1 \mathrm{~ms}$ duration, $4 \mathrm{~ms}$ apart).

All thresholds were determined as the mean of two measurements.

\section{EVOKED POTENTIALS}

Evoked vertex potentials were assessed by stimulating the oesophageal mucosa and the sternal skin at amperages 1.3 times the previously determined pain thresholds. The evoked potentials were recorded with a platinum needle electrode (Disa 25C04, Copenhagen, Denmark) inserted at $C_{z}$ with reference to linked earlobes as previously described. ${ }^{19} 20$ The electroencephalogram was filtered by a second order filter $(0.5-12 \mathrm{~Hz})$, amplified, and sampled by a computer at $64 \mathrm{~Hz}$. On average 16 stimuli were used since this is sufficient to obtain an acceptable signal to noise ratio. ${ }^{23} \mathrm{~A}$ test stimulus was delivered before each series, and $2 \mathrm{~s}$ before each stimulus the subjects received an auditory warning stimulus to minimise variability. ${ }^{24}$ The subjects were asked to keep their eyes open, and eye movements which could contaminate the evoked potentials were monitored continuously. The peaks of the evoked potential signal were designated $\mathrm{N}$ for negative deflections and $\mathrm{P}$ for positive. Numbers were given to the peaks in order of appearance after the stimulus. The $\mathrm{P} 1, \mathrm{~N} 1$, and $\mathrm{P} 2$ peaks were determined independently by two blinded observers. The peak to peak amplitudes $(\mathrm{P} 1 / \mathrm{N} 1, \mathrm{~N} 1 / \mathrm{P} 2)$ in $\mu \mathrm{V}$ and latencies of $\mathrm{P} 1, \mathrm{~N} 1$ and $\mathrm{P} 2$ in ms with respect to trigger onset were measured by computer.

\section{STATISTICS}

The Mann-Whitney test for unpaired observations was used to compare median values between groups. Bivariate correlations were evaluated by Pearson's least square regression. $P<0.05$ was considered significant.

\section{ETHICS AND SAFETY}

The study was approved by the local ethics committee. Written informed consent was obtained from all subjects and the entire study was carried out in a cardiac clinic with continuous monitoring by electrocardiogram, intravenous access established, and resuscitation stand by.

\section{Results}

There was no significant difference in age between patients and controls. All subjects completed the study. One patient had atrial capture during continuous oesophageal stimu- 


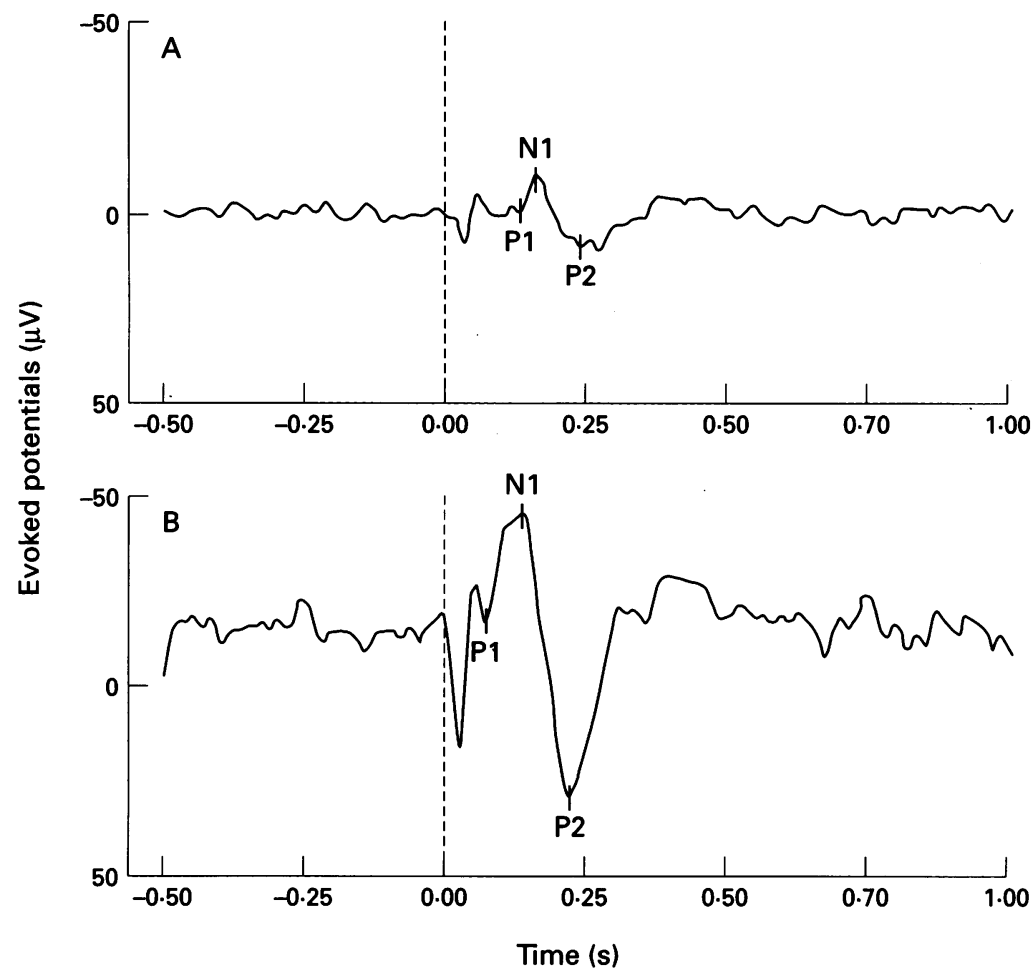

Figure 1 Brain evoked potentials following electrical stimulation of the oesophageal mucosa at 1.3 times the pain threshold. (A) Female patient with a 6 year history of angina despite normal coronary angiogram. (B) Female control.
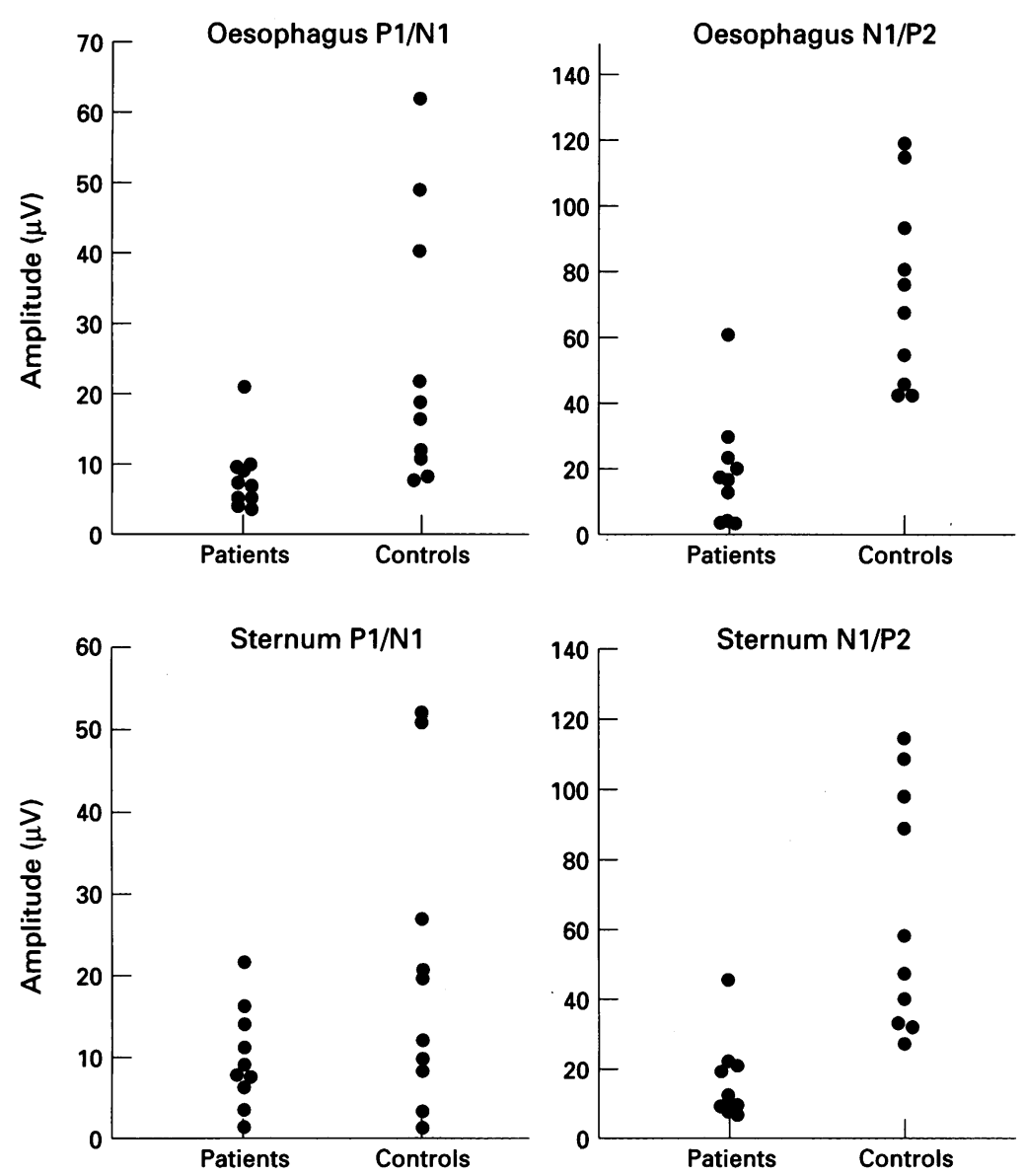

Figure 2 Individual values of evoked potential amplitudes of 10 patients with angina despite normal coronary angiograms and 10 healthy controls. Top panels show values following electrical stimulation of the oesophageal mucosa; bottom panels show values following electrical stimulation of the sternal skin. The peaks of the evoked potential signal were designated $N$ for negative deflections and $P$ for positive. The peak to peak (P1/N1, $N 1 / P 2$ ) amplitudes in $\mu V$ are shown. lation which returned to sinus rhythm immediately after stimulus cessation. ST segment depression of the electrocardiogram was not seen in any subjects during the study.

\section{SENSATION}

Angina similar to their habitual pain episodes was provoked in two patients following single oesophageal stimuli and in seven following continuous stimulation. Continuous oesophageal stimulation resulted in the following distant projections in four patients: (1) to the shoulders and the proximal part of both arms, (2) to the neck and jaws, (3) to the left hemithorax, and (4) to the right elbow and left radial fingers. The controls described the nociceptive oesophageal stimulation as either "artificial" or "resembling heartburn". No patients experienced projection following skin stimulation and no controls reported projection from either oesophageal or cutaneous stimulation.

\section{THRESHOLD DETERMINATION}

Oesophageal thresholds of perception (median (range), patients: $3.2 \mathrm{~mA}(2.1$ to $7.8 \mathrm{~mA})$; controls: $5.0 \mathrm{~mA}(3.0$ to $7.5 \mathrm{~mA}))$ and of pain (patients: $15.8 \mathrm{~mA}(7.5$ to $37.0 \mathrm{~mA})$; controls: $15.8 \mathrm{~mA}(6.0$ to $25.0 \mathrm{~mA}))$ were not statistically different between groups $(P=0.22$ and 0.97 , respectively). The oesophageal pain threshold of summation (patients: $16.3 \mathrm{~mA}$ (6.0 to $27.5 \mathrm{~mA})$; controls: $7.3 \mathrm{~mA}(4.5$ to $16.0 \mathrm{~mA})$ ) was significantly higher in the patient group $(P=0.02)$.

The sternal skin threshold of perception (patients: $0.73 \mathrm{~mA}(0.28$ to $1.00 \mathrm{~mA})$; controls: $0.83 \mathrm{~mA}(0.48$ to $1.38 \mathrm{~mA})$ ), of pain (patients: $7.38 \mathrm{~mA}(2.63$ to $13.00 \mathrm{~mA})$; controls: 5.94 $\mathrm{mA}(3.38$ to $8.80 \mathrm{~mA}))$, and the pain threshold of summation (patients: $6.00 \mathrm{~mA}(1.88$ to 14.0 $\mathrm{mA})$; controls: $5.75 \mathrm{~mA}(4.38$ to $15.00 \mathrm{~mA})$ ) did not differ between groups $(P=0 \cdot 20,0 \cdot 53$, and $0 \cdot 82$, respectively).

\section{BRAIN EVOKED POTENTIALS}

Evoked potentials were recorded in all $20 \mathrm{sub}-$ jects. The amplitudes of the P1/N1 and N1/P2

Table 2 Latencies and interpeak amplitudes of vertex evoked potentials (measurements taken at $\mathrm{Cz}$ ) in 10 patients with angina and normal coronary angiograms and in 10 controls following electrical stimulation of the oesophagus $38 \mathrm{~cm}$ from the nares and of the sternal skin. The evoked potentials were measured as an average of 16stimulus series 1.3 times the previous determined pain threshold. Values are median and (quartiles)

\begin{tabular}{lll}
\hline & Patients $(n=10)$ & Controls $(n=10)$ \\
\hline Latency $(m s)$ & & \\
Oesophagus & & \\
P1 & $106(96-131) \mathrm{NS}$ & $102(70-109)$ \\
N1 & $156(135-162) \mathrm{NS}$ & $141(125-156)$ \\
P2 & $219(219-232) \mathrm{NS}$ & $227(226-246)$ \\
Sternum & & \\
P1 & $102(94-109) \mathrm{NS}$ & $86(78-100)$ \\
N1 & $125(117-148) \mathrm{NS}$ & $133(133-139)$ \\
P2 & $203(188-219) \star$ & $211(211-242)$ \\
Amplitude $(\mu V)$ & & \\
Oesophagus & & \\
P1/N1 & $7 \cdot 2(5 \cdot 4-9 \cdot 6) \star \star$ & $17 \cdot 5(10 \cdot 8-40 \cdot 2)$ \\
N1/P2 & $16.5(4 \cdot 4-23 \cdot 0) \star \star$ & $71 \cdot 8(45 \cdot 6-93 \cdot 4)$ \\
Sternum & & \\
P1/N1 & $8 \cdot 4(6 \cdot 1-14 \cdot 1) \mathrm{NS}$ & $15 \cdot 7(8 \cdot 1-27 \cdot 1)$ \\
N1/P2 & $12 \cdot 2(9 \cdot 8-21 \cdot 7) \star \star$ & $53 \cdot 4(33 \cdot 7-98 \cdot 9)$ \\
\hline
\end{tabular}

$\mathrm{N}$, negative; $\mathrm{P}$, positive, ${ }^{\star} \mathrm{P}<0.05$; ${ }^{\star \star P}<0.001$. 
peaks following oesophageal stimulation and of the N1/P2 peaks following sternal stimulation were significantly lower in patients compared with controls (table 2, figs 1 and 2). The oesophageal pain thresholds and the N1/P2 amplitudes of the evoked potentials correlated in the patient group $(r=0.97, y=10.2+$ $1 \cdot 8 \mathrm{x})$ but not in controls $(r=0 \cdot 26, \mathrm{y}=43.3+$ $2 \cdot 3 \mathrm{x})$. The sternal pain thresholds and the N1/P2 amplitudes showed some correlation (patients: $r=0.61, \mathrm{y}=1.83+2 \cdot 3 \mathrm{x}$; controls, $r$ $=0.62, y=17 \cdot 3+12 \cdot 2 x)$. The only latency that differed between patients and controls was that of the P2 peak following sternal stimulation (table 2).

\section{Discussion}

The results of the present study suggest that patients with angina, despite normal coronary angiograms, have altered processing of nociceptive inputs. Despite similar pain thresholds the evoked potential amplitudes following nociceptive electrical stimulation of both the oesophagus and the skin were substantially lower in patients than in controls. Only a few studies of evoked potential responses have been carried out in patients with visceral pain. Reduced evoked potential amplitudes have been found after nociceptive somatosensory stimulation of chronic cancer pain patients, with the low amplitudes apparently restricted to input from pain affected regions. ${ }^{25}$ Reduced evoked potentials were also described following non-nociceptive oesophageal balloon distension in patients with angina-like chest pain, in a study where the mean age of the control group was significantly lower than that of the patient group. ${ }^{26}$ By contrast, a study of patients with chronic burning pain in the mouth showed increased brain evoked potential amplitudes to intraoral pain stimulation compared to a matched control group. ${ }^{27}$ Using positron emission tomography, Rosen et al recently showed that dobutamine-induced angina in patients with coronary artery disease resulted in thalamic and frontal cortical activity during angina but only the thalamic activity persisted through the postangina scan. ${ }^{28}$ They concluded that the thalamus may act as a gate to afferent pain signals. A strong thalamic gate in patients with angina and normal coronary angiograms could also contribute to explaining the reduced vertex evoked potentials of the present study.

Brain evoked potentials are generally regarded as the summated electrical fields of a large number of neuronal membranes acting in synchrony. ${ }^{29}$ Age, neuropathy, and the level of arousal are critical factors for the amplitudes and latencies of brain evoked potentials. ${ }^{30-32}$ In the present study there were no differences in age (or sex) between patients and controls, no subjects had endocrinological disorders or neuropathy, and in order to reduce and standardise arousal, test stimuli were applied to make subjects familiar with the study regimen. Amplitude increases of the evoked potential responses could be due to additional recruitment of non-nociceptive nerve fibres. ${ }^{29}$ However, there is no reason to believe that such sources of error might influence the results in a specific direction when comparing findings of patients and controls. We have previously shown that there was no systematic difference in evoked potential latency values following oesophageal stimulation on two occasions six months apart. ${ }^{20}$ However, in that study we found a significantly higher amplitude in the first compared with the second measurement, which could reflect the fact that subjects were more aroused at their first session. In the present study no subjects had any previous experience with this kind of investigation. Previous studies have shown positive correlations between evoked potential amplitudes and the intensity of pain, and little relation between amplitudes and stimulus intensity (cited in ${ }^{29}$ ) as in the present study.

A lowered threshold for visceral pain in patients with angina despite normal coronary angiograms has been suggested. ${ }^{33}$ In the present study no thresholds differed between patients and controls except the visceral threshold of summation, which was higher in the patient group. An explanation which combines both the finding of normal pain thresholds and reduced brain evoked potentials could be a raised concentration of endorphins in the patient group since morphine and other opiates are known not to affect acute pain thresholds, ${ }^{34}$ despite the fact that they reduce the amplitudes of brain evoked potentials..$^{35} 36$ Electrical stimulation of the oesophageal mucosa did simulate angina qualitatively in seven of 10 patients and caused pain projection to remote areas such as the jaws, the upper extremities, and fingers in four. The controls reported the sensation as "artificial" or "resembling heartburn" and no controls reported projection. However, the anatomical specificity of oesophageal provocation is questionable: oesophageal balloon distension in patients with atherosclerotic heart disease may reproduce chest pain ${ }^{37-39}$ and coronary blood flow may be altered in relation to oesophageal balloon distension ${ }^{40}$ and acid perfusion. ${ }^{41}$ This is in line with the central convergence hypothesis of cardiac and oesophageal visceral pathways entering the spinal cord from the sympathetic limb of the autonomic nervous system (oesophagus: C8-T10; heart: T1T4).$^{4243}$ In addition, reference of visceral pain to somatic structures near the midline contributes to the fact that pain originating in one viscus cannot easily be differentiated from pain originating in another viscus by the quality, localisation, or intensity of the sensation alone. ${ }^{44}$ Therefore positive oesophageal provocative procedures do not necessarily imply that the usual pain of the patient arises from the oesophagus.

Temporal summation, that is, repeated nociceptive stimuli of equal intensity building up so that stimuli in the end of a series are experienced as more painful than the first stimuli, ${ }^{45}$ was found in all subjects. The fact that the oesophageal but not the cutaneous pain threshold of summation was higher in the 
patient group might be a result of central nervous system modulation of visceral nociceptive input. It has previously been shown that pain summation is of importance for hyperexcitability related to cutaneous pain, ${ }^{46}$ whereas further studies are needed to evaluate the pathophysiological importance in visceral pain syndromes.

A key question in studying patients with angina and normal coronary angiograms is whether they suffer from unrecognised cardiac disease. One cardiological hypothesis of the underlying mechanism of chest pain in this patient group has been "microvascular angina"-that is, a reduced ability of the minor cardiac vessels to dilate. ${ }^{4748}$ This idea has recently lost credence somewhat since it is hard to imagine that restrictions in cardiac flow conceivably capable of producing pain are almost never associated with detectable myocardial ischaemia.4950 Abnormal cardiac nociception represents one of the most recent hypotheses. Clinical observations during cardiac catheterisation have shown that intracardiac catheter manipulation may provoke angina in chest pain patients with normal coronary angiograms, in contrast to observations in other patient categories. ${ }^{151}$ Many clues to an extracardiac disorder have been provided, with the majority of studies being conducted in the search of an oesophageal abnormality. ${ }^{52} 53$ Musculoskeletal disorders of the chest and back may also account for anginal attacks. ${ }^{14-16}$ Neuroticism, "vital exhaustion", "type A behaviour", ${ }^{11}$ panic disorders, ${ }^{13}$ and general psychiatric illness ${ }^{12}$ have been associated with chest pain and normal coronary angiograms.

The substantially reduced amplitudes of brain evoked potentials of these patients, as in other conditions of chronic pain, stress the fact that angina-despite a normal coronary angiogram - is a chronic, disabling disease. The findings indicate altered central nervous system responses particularly to visceral but also to somatosensory nociceptive input in these patients. The study does not allow us to draw conclusions about a possible oesophageal role in the origin of pain of this patient group but it supports the concept of a general abnormality of nociception.

The study was supported by Kirsten Anthonius's Mindelegat, the Danish Heart Foundation, and the Danish Basic Research Foundation.

1 Cannon RO, Quyyumi AA, Schenke WH, et al. Abnorma cardiac sensitivity in patients with chest pain and normal coronary arteries. $\mathcal{f}$ Am Coll Cardiol 1990;16:1359-66.

2 Shapiro LM, Crake T, Poole Wilson PA. Is altered cardiac sensation responsible for chest pain in patients with normal coronary arteries? Clinical observation during diac catheterisation. Br Med 7 Clin Res Ed 1988;296: $170-1$.

3 Lagerqvist B, Sylven C, Waldenstrom A. Lower threshold for adenosine-induced chest pain in patients with angin and normal coronary angiograms. Br Heart $\mathcal{F} 1992 ; 68$ : $282-5$.

4 Opherk D, Zebe H, Weihe E, et al. Reduced coronary dilatory capacity and ultrastructural changes of the tory capacity and ultrastructural changes of the myocardium in patients with angina pectoris but no

5 Rosano GM, Ponikowski P, Adamopoulos S, et al. Abnormal autonomic control of the cardiovascular system in syndrome X. Am 7 Cardiol 1994;73:1174-9.

6 Frøbert O, Molgaard H, Bøtker HE, Bagger JP. Autonomic balance in patients with angina and normal coronary angiogram. Eur Heart $\mathcal{f} 1995$ (in press)

7 Bernstein LM, Fruin RC, Pacini R. Differentiation of oesophageal pain from angina pectoris: role of the oesophageal pain from angina pectoris: role of the oesopha.

8 Brand DL, Martin D, Pope CE. Oesophageal manometrics in patients with angina-like chest pain. Dig Dis 1977;22: 300-4

9 Cannon RO, Cattau ELJ, Yakshe PN, et al. Coronary flow reserve, oesophageal motility, and chest pain in patients with angiographically normal coronary arteries. $\mathrm{Am} \mathcal{f}$ Med 1990;88:217-22.

10 Bøtker HE, Møller N, Ovesen P, et al. Insulin resistance in microvascular angina (syndrome $X)$. Lancet 1993;342: $136-40$.

11 Roll M, Theorell T. Acute chest pain without obvious organic cause before age 40 - personality and recent life events. $\mathcal{F}$ Psychosom Res 1987;31:215-21.

2 Colgan SM, Schofield PM, Whorwell PJ, Bennett DH Brooks NH, Jones PE. Angina-like chest pain: a joint medical and psychiatric investigation. Postgrad Med $\mathcal{F}$ 1988;64:743-6.

13 Beitman BD. Panic disorder in patients with angiographically normal coronary arteries. Am $\mathcal{f}$ Med 1992;92: 33-40S

14 Nachlas IW. Pseudo-angina pectoris originating in the cervical spine. $\mathcal{F} A M A$ 1934;103:323-5.

5 Allison DR. Pain in the chest wall simulating heart disease. BMF 1950;i:332-6.

16 Davis D, Ritvo M. Osteoarthritis of the cervicodorsal spine (radiculitis) simulating coronary-artery disease. Clinical and roentgenologic findings. $N$ Engl $f \mathrm{Med}$ 1948;238: and roentge 66.

17 Cannon RO, Benjamin SB. Chest pain as a consequence of abnormal visceral nociception. Dig Dis Sci 1993;38: 193-6.

18 Cannon RO, Quyyumi AA, Mincemoyer R, et al. Imipramine in patients with chest pain despite normal coronary mine in patients with chest pain despite normal
angiograms. N Engl $f$ Med 1994;330:1411-7.

19 Frøbert O, Arendt-Nielsen L, Bak P, Andersen OK, Funch-Jensen P, Bagger JP. Electrical stimulation of the oesophageal mucosa: perception and brain evoked potentials. Scand f Gastroenterol 1994;29:776-81.

20 Frøbert O, Arendt-Nielsen L, Bak P, Funch-Jensen $P$ Bagger JP. Oesophageal sensation assessed by electrical stimuli and brain evoked potentials. A new model for visceral nociception. Gut 1995;37:603-9.

21 Rasmussen K, Bagger JP, Bottzauw J, Henningsen P Prevalence of vasospastic ischaemia induced by the cold pressor test or hyperventilation in patients with severe angina. Eur Heart $\mathcal{F}$ 1984;5:354-61.

22 Bagger JP, Nielsen TT, Thomassen A. Reproducibility of coronary haemodynamics and cardiac metabolism during pacing-induced angina pectoris. Clin Physiol 1985;5: 359-70.

23 Arendt-Nielsen L. First pain event related potentials to argon laser stimuli: recording and quantification. $\mathcal{F}$ Neurol Neurosurg Psychiatry 1990;53:398-404.

24 Arendt-Nielsen L, Bjerring P. Selective averaging of argon laser induced pre-pain and pain related cortical laser induced pre-pain and pain related
responses. Neurosci Methods 1988;24:117-23.

25 Gibson SJ, Le Vasseur SA, Helme RD. Cerebral eventrelated responses induced by $\mathrm{CO}_{2}$ laser stimulation in subjects suffering from cervico-brachial syndrome. Pain 1991;47:173-82.

26 Smout AJ, DeVore MS, Dalton CB, Castell DO. Cerebral potentials evoked by oesophageal distension in patients potentials evoked by oesophageal distension in patien

27 Svensson P, Bak P, Arendt-Nielsen L, Kaaber S, Bjerring $P$. Response of BMS (burning mouth syndrome) patients to brief nociceptive heat and mechanical stimuli. $f$ Orofacial Pain 1993;7:70-6.

28 Rosen SD, Paulesu E, Frith CD, et al. Central nervous pathways mediating angina pectoris. Lancet 1994;344: 147-50.

29 Chudler EH, Dong WK. The assessment of pain by cerebral evoked potentials. Pain 1983;16:221-44.

30 Lüders $H$. The effects of aging on the wave form of the somatosensory cortical evoked potential. Electroencephalogr Clin Neurophysiol 1970;29:450-60.

31 Rathmann W, Enck P, Frieling T, Gries FA. Visceral afferent neuropathy in diabetic gastroparesis. Diabetes Care 1991;14:1086-9.

32 Arendt-Nielsen L. Characteristics, detection, and modulation of laser-evoked potentials. Acta Anaesth Scand 1994;38:suppl 101.

33 Janssens JP, Vantrappen G. Irritable oesophagus. Am $\mathcal{f}$ Med 1992;92:27-32S.

34 Brennum J, Arendt-Nielsen L, Horn A, Secher NH, Jensen TS. Quantitative sensory examination during epidural anaesthesia and analgesia in man: effects of morphine. Pain 1993;52:75-83.

35 Buchsbaum MS, Davis GC, Coppola R, Naber D. Opiate pharmacology and individual differences. II. Somatosensory evoked potentials. Pain 1981;10:367-77.

36 Davis GC, Buchsbaum MS, Naber D, Van Kammen DP. Effect of opiates and opiate antagonists on somatosenEffect of opiates and opiate antagonists on somatosen-
sory evoked potentials in patients with schizophrenia and sory evoked potentials in patients with schizophre
normal adults. Adv Biol Psychiatry 1980;4:73-80.

normal adults. Adv Biol Psychiatry 1980;4:73-80.
37 Kramer P, Hollander W. Comparison of experimental oesophageal pain with clinical pain of angina pectoris and oesophageal pain with clinical pain of angina pectoris and
oesophageal disease. Gastroenterology 1955;29:713-43. 38 Morrison LM, Swalm WA. Role of the gastrointestinal 
tract in production of cardiac symptoms. $\mathcal{F} \mathrm{Am}$ Coll Cardiol 1940;114:217-23.

39 Stürup GK Visceral pain. Plethysmographic "pain reactions". Dilatation of the oesophagus. London: HK Lewis, 1940.

40 Gayheart PA, Gwirtz PA, Bravenec JS, Longlet N, Jones CE. An alpha-adrenergic coronary constriction during oesophageal distention in the dog. $f$ Cardiovasc Pharmacol 1991;17:747-5

41 Chauhan A, Petch MC, Schofield PM. Effect of oesophageal acid instillation on coronary blood flow. Lancet 1993;341:1309-10.

42 Sylven C. Angina pectoris. Clinical characteristics, neurophysiological and molecular mechanisms. Pain 1989;36: $145-67$.

43 Garrison DW, Chandler MJ, Foreman RD. Viscerosomatic convergence onto feline spinal neurons from oesophagus, heart and somatic fields: effects of inflammation. Pain 1992;49:373-82.

44 Ness TJ, Gebhart GF. Visceral pain: a review of experimental studies. Pain 1990;41:167-234.

45 Arendt-Nielsen L, Brennum J, Sindrup S, Bak P. Electrophysiological and psychophysical quantification of temporal summation in the human nociceptive system. Eur $\mathcal{F}$ Appl Physiol 1994;68:266-73.

46 Dubner R. Pain and hyperalgesia following tissue injury: new mechanisms and new treatments. Pain 1991;44:
213-4.

47 Sax FL, Cannon RO, Hanson C, Epstein SE. Impaired forearm vasodilator reserve in patients with microvascufunction? N Engl f Med 1987;317:1366-70.

48 Cannon RO, Epstein SE. "Microvascular angina" as a cause of chest pain with angiographically normal coronary arteries. Am f Cardiol 1988;61:1338-43.

49 Camici PG, Gistri R, Lorenzoni R, et al. Coronary reserve and exercise ECG in patients with chest pain and normal coronary angiograms. Circulation 1992;86:179-86.

50 Rosen SD, Uren NG, Kaski JC, Tousoulis D, Davies GJ, Camici PG. Coronary vasodilator reserve, pain perception, and sex in patients with syndrome $\mathrm{X}$. Circulation 1994;90:50-60.

51 Chauhan A, Mullins PA, Thuraisingham SI, Taylor G, Petch MC, Schofield PM. Abnormal cardiac pain per-
ception in syndrome X. $f \mathrm{Am}$ Coll Cardiol 1994;24: 329-35.

52 Hewson EG, Dalton CB, Richter JE. Comparison of oesophageal manometry, provocative testing, and ambulatory monitoring in patients with unexplained chest pain. Dig Dis Sci 1990;35:302-9.

53 Vantrappen G, Janssens J, Ghillebert G. The irritable oesophagus- $\mathrm{a}$ frequent cause of angina-like pain. Lancet 1987;i:1232-4. 